\title{
MENINGKATKAN HASIL BELAJAR BERMAIN TONNIS MELALUI PENDEKATAN TEACHING GAME FOR UNDERSTANDING (TGFU)
}

\author{
Mega Widya Putri \\ Pendidikan Jasmani Kesehatan dan Rekreasi \\ JPOK FKIP Universitas Sebelas Maret Surakarta \\ E-mail: megawidyaputri60@yahoo.com
}

Diterima: 15 November 2017; Lolos: 18 November 2017; Dipublikasikan: 18 November 2017

\begin{abstract}
Abstrak
Penelitian ini bertujuan meningkatkan hasil belajar bermain tonnis dalam pembelajaran tonnis pada siswa kelas IV SD Negeri 2 Gedong Karanganyar tahun ajaran 2013 / 2014 melalui penerapan pendekatan Teaching Games for Undestanding (TGfU). Penelitian ini merupakan penelitian tindakan kelas (PTK). Subjek penelitian adalah siswa kelas IV SD Negeri 2 Gedong Karanganyar yang berjumlah 22 siswa yang terdiri dari 10 siswa putra dan 12 siswa putri. Sumber data dalam penelitian ini berasal dari guru dan siswa. Teknik pengumpulan data adalah dengan observasi dan penilaian kemampuan bermain tonnis dan hasil belajar bermain bola kecil tonnis. Analisis data menggunakan teknik deskriptif yang didasarkan pada analisis kualitatif dengan prosentase. Berdasarkan hasil analisis data yang diperoleh, pada siklus I, hasil belajar bermain tonnis siswa mencapai $63,63 \%$ atau sebanyak 13 siswa dari 22 siswa telah masuk kriteria tuntas. Pada siklus II hasil belajar bermain tonnis siswa yang masuk kriteria tuntas juga meningkat menjadi $86,36 \%$ atau 18 siswa masuk pada kriteria tuntas dan 4 lainya belum tuntas. Kesimpulan dari penelitian ini adalah penggunaan pendekatan Teaching Games for Understanding (TGfU) dapat meningkatkan hasil belajar bermain tonnis siswa kelas IV SD Negeri 2 Gedong Karanganyar tahun ajaran 2013 / 2014.
\end{abstract}

Kata kunci: Hasil Belajar, bermain tonnis, TGfU (Teaching Game for Understanding), pendekatan pembelajaran, olahraga permainan.

\section{IMPROVING THE RESULT OF LEARNING TONNIS WITH APPROACH OF TEACHING GAME FOR UNDERSTANDING (TGFU) IN STUDENTS OF CLASS IV IN ELEMENTARY SCHOOL 2 GEDONG KARANGANYAR IN ACADEMIC YEAR 2013/2014}

\begin{abstract}
This study aims to improve the result of learning tonnis for students of class IV in Elementary School 2 Gedong Karanganyar in academic year 2013/ 2014 through application of Teaching Games for undestanding approaches (TGfU). This study was action research or Penelitian Tindakan Kelas (PTK). The research was done on two cycle, each cycle consisting of planning, action, observation, and reflection. The researcher used subjects in this research. They are students of class IV in Elementary School 2 Gedong Karanganyar, which amounts to 22 students consisting of 10 boys and 12 girls. The data came from teachers and students. The technique of data collection was the observation and assessment

Email : megawidyaputri60@yahoo.com

No Handphone : 081225618771

(C)2017 UN PGRI Kediri

p-ISSN: $2548-7833$

e-ISSN: $2477-3379$
\end{abstract}


capabilities in tonnis, learning activities and result of learning playing small ball in tonnis. Analysis of data used descriptive technique based on a qualitative analysis of the percentage. From result of analysis was gotten significant increase fro pra-cycle to first cycle and from first cycle to second cycle. In the first cycle of learning result of students playing tonnis reached $63,63 \%$ or as many as 13 students of the 22 students have completion criteria. In the second cycle of learning result of students who have the play tonnis completion criteria also increased to $86,36 \%$ or 18 students have the criteria and 4 other completely unfinished. The conclusion of this study is the use of approach to Teaching Games for Understanding (TGfU) can improving the result of learning tonnis in students of class IV in Elementary School 2 Gedong Karanganyar in academic year 2013/ 2014.

Keywords: The learning result, tonnis, TGfU (Teaching Games for Understanding), the learning approach, sports games.

\section{PENDAHULUAN}

Salah satu yang diajarkan dalam pendidikan jasmani adalah cabang olahraga permainan bola kecil, terdapat banyak macam cabang olahraga permainan bola kecil, misalnya : kasti, rondes, tonnis, bola tangan dan banyak lainya. Melalui pembelajaran permainan banyak manfaat yang diperolehnya, antara lain untuk mendatangkan kegembiraan, kesenangan, kepuasan bagi pelakunya dan sebagai salah satu alat untuk mendidik manusia untuk meningkatkan kualitas diri. Menguasai teknik dasar bermain tonnis merupakan faktor yang fundamental agar memiliki keterampilan bermain tonnis yang baik. Macam-macam teknik dasar tonnis harus dikuasai diantaranya : servis, forehand, backhand, voli, smash. Dengan menguasai teknik dasar bermain tonnis, maka akan meningkatkan kualitas penampilannya baik secara individu maupun kolektif (tim).

Maka mengenalkan berbagai macam dasar-dasar dalam olahraga permainan adalah salah satu yang di ajarkan dalam pembelajaran pendidikan jasmani. Pembelajaran harus menyesuaikan dengan karakteristik siswa, tingkat kompleksitas yang dapat diberikan dari materi pembelajaran tersebut. Dalam kurikulum yang ada setiap jenjang pendidikan memiliki tuntutan yang berbeda-beda yang telah disesuaikan dengan karakteristik siswa.

Kesulitan-kesulitan yang dihadapi siswa dalam belajar permainan bola kecil tonnis menuntut seorang guru penjas harus memiliki kreatifitas 
dalam membelajarkan materi tersebut. Permasalahan umum dalam pembelajaran pendidikan jasmani adalah kurangnya peran aktif siswa dalam kegiatan belajar, siswa hanya melakukan apa yang diperintahkan guru tanpa memunculkan sebuah masalah dimana siswa diminta untuk berfikir dan memecahkan masalah. Proses pembelajaran yang berlangsung belum mewujudkan adanya partisipasi siswa secara penuh. Siswa berperan sebagai objek pembelajaran, yang hanya mendengarkan dan mengaplikasikan apa yang disampaikan oleh guru.

Pada pembelajaran yang dilakukan guru saat ini cenderung menggunakan pendekatan yang mendasarkan pada olahraga prestasi dalam pengajarannya, guru menerapkan pendekatan penguasaan pada teknik dasar. Pendekatan seperti itu menjadikan anak kurang senang atau bahkan merasa frustasi untuk melakukan program pendidikan jasmani karena mereka tidak mampu dan sering gagal untuk melaksanakan tugas yang diberikan dalam bentuk kompleks. Pembelajaran terkesan monoton dan membosankan. Guru dalam hal ini harus memiliki kemampuan untuk melakukan modifikasi keterampilan yang hendak diajarkan agar sesuai dengan tingkat perkembangan anak. Kesulitan-kesulitan yang dihadapi siswa harus dicarikan solusi yang tepat, sehingga tujuan pembelajaran dapat tercapai, maka digunakan pendekatan pembelajaran Teaching Game for Understanding (TGfU).

Menurut Pambudi (2011) "Teaching Game for Understanding (TGfU) adalah suatu pendekatan pembelajaran pendidikan jasmani untuk memperkenalkan bagai mana anak mengerti olehraga melalui bentuk konsep dasar bermain".

Menurut Thorpe (2001) bahwa Pembelajaran Pendekatan Taktik "mempermudah siswa untuk mempelajari tentang permainan dan mempraktikkan teknik dalam konteks permainan bukannya terpisah dari permainan tersebut" (Griffin \& Butler, 2005:50).

Sedangkan menurut pendapat Webb \& Pearson (2008) menyatakan bahwa, TGfU menempatkan penekanan pada bermain, di mana masalah taktis dan strategis yang berpose di lingkungan permainan 
yang dimodifikasi, akhirnya menggambar atas siswa untuk membuat keputusan.

Pendekatan TGfU merupakan salah satu pendekatan yang mengakomodir kebutuhan anak dalam bermain. Guru penjas sebagai pengelola kelas berperan sebagai fasilitator pembelajaran dan tidak menjadi domain dengan pembelajaran contoh-contoh seperti yang terjadi pada pembelajaran yang berbasis teknik. Pendekatan TGfU juga dapat dijadikan sebagai sebuah inovasi yang menuju kepada perbaikan pembelajaran penjas di sekolah.

Berdasarkan permasalahan yang telah dikemukakan diatas maka diangkat judul "Bagaimanakah Meningkatkan Hasil Belajar Bermain Tonnis Melalui Pendekatan Teaching Game for Understanding (TGfU) Pada Siswa Kelas IV SD Negeri 2 Gedong Karanganyar Tahun Pelajaran 2013 / 2014".

\section{METODE PENELITIAN}

Penelitian Tindakan Kelas ini dilaksanakan di SD Negeri 02 Gedong Karanganyar, Jln Raya Mojogedang Km 6 Gedong, Karanganyar. Penelitian Tindakan Kelas ini dilaksanakan pada bulan Maret sampai bulan April 2014. Subjek penelitian ini adalah siswa kelas IV SD Negeri 02 Gedong Karanganyar, Jln Raya Mojogedang Km 6 Gedong, Karanganyar. Tahun Ajaran 2013 / 2014 yang berjumlah 22 siswa. Dengan rician siswa putra : 10 Anak dan siswa putri : 12 anak.

Teknik pengumpulan data dalam Penelitian Tindakan Kelas (PTK) ini terdiri dari :

1. Tes: dipergunakan sebagai teknik pengumplan data untuk mengukur kemampuan siswa dalam penguasaan materi pembelajaran bermain tonnis dalam bentuk tes groundstroke.

2. Observasi: digunakan sebagai teknik untuk mengumpulkan data tentang aktivitas siswa dalam mengikuti proses belajar mengajar saat penerapan Teaching Game for Understanding (TGfU). 


\section{HASIL PENELITIAN DAN PEMBAHASAN}

\section{A. Deskripsi Pra Tindakan}

Siswa kelas VI SD Negeri 2 Gedong Karanganyar Tahun Pelajaran 2013/2014 yang mengikuti materi pelajaran pendidikan jasmani dan olahraga bermain tonnis adalah 22 siswa, terdiri atas 10 siswa putra dan 12 siswa putri. Dalam pembelajaran materi tonnis yang terdapat dalam silabus sudah pernah diajarkan di kelas tersebut seperti yang telah di rencanakan dalam silabus tetapi ada kesulitan kesulitan yang dihadapi siswa dalam materi permainan bola kecil tonnis sehingga keterampilan bermain tonnis belum sesuai, oleh karena itu hasil belajar bermain tonnis selama pembelajaran berlangsung masih belum maksimal. Berdasarkan hasil data awal, diketahui bahwa hanya ada beberapa siswa yang sudah mampu melakukan groundstoke tonnis dengan baik atau memperoleh nilai 75. Dari hasil belajar groundstoke tonnis hanya ada 6 anak $(27,27 \%)$ yang lulus. Dari data tersebut, menunjukkan bahwa hasil belajar siswa dalam melakukan gerakan groundstoke masih rendah. Untuk memperbaiki dan meningkatkan hasil belajar siswa dalam proses pembelajaran bermain tonnis, maka akan dilakukan tindakan berupa mempebrikan pembelajaran dengan menggunakan pendekatan teaching game for understanding. Dari hasil observasi awal, ada dua siklus yang diterapkan untuk menyelesaikan dan menjawab permasalahan yang terjadi di dalam kelas. Pada setiap siklus masing masing menggunakan pendekatan pembelajaran teaching game for understanding dalam kegiatan belajar mengajar yang berlangsung. Kegiatan selanjutnya setelah observasi awal yaitu perencanaan, pelaksanaan, pengamatan serta refleksi terhadap tindakan.

\section{Deskripsi Hasil Tindakan Tiap Siklus}

\section{Siklus 1}

Tindakan I dilaksanakan selama tiga kali pertemuan (dilaksanakan selama 2 × 35 menit). Adapun tahapan-tahapan yang dilakukan pada siklus I adalah sebagai berikut :

\section{a. Perencanaan Tindakan I}

Rencana pelaksanaan tindakan I sebagai berikut: 
a) Peneliti bersama kolabolator merancang skenario penggunaan alat bantu pembelajaran

b) Peneliti dan kolabolator menyusun Rencana Pelaksanaan Pembelajaran (RPP)

c) Peneliti dan kolabolator menyiapkan alat pembelajaran

d) Peneliti dan kolabolator menyusun instrumen penilaian menggunakan GPAI

e) Peneliti dan kolabolator menentukan lokasi pelaksanaan tindakan I, yakni di lapangan batminton SD Negeri 2 Gedong Karanganyar.

\section{b. Pelaksanaan Tindakan I}

Tindakan I dilaksanakan selama tiga kali pertemuan. Masingmasing pertemuan dilaksanakan selama $2 \times 35$ menit.

\section{1) Pertemuan I}

Pelaksanaan tindakan tersebut adalah sebagai berikut:

a) Peneliti dan kolabolator menyiapkan siswa, berdoa, presensi, memberikan motivasi dan penjelasan materi bermain tonnis.

b) Peneliti dan kolabolator menyampaikan motivasi dan tujuan pembelajaran.

c) Peneliti dan kolabolator memberikan pemanasan dalam bentuk permainan.

d) Peneliti dan kolabolator mengumpulkan siswa dan memberikan arahan permainan tonnis menggunakan pendekatan TGfU 3 lawan 3 dan 4 lawan 4.

e) Peneliti dan kolabolator memberikan bimbingan dan evaluasi kepada siswa tentang gerakan yang dilakukannya.

f) Peneliti dan kolabolator mengumpulkan siswa untuk berdiskusi tentang materi yang dilakukan, dan siswa berkumpul dan menjawab pertanyaan.

g) Pelajaran di akhiri dengan berdoa dan siswa di bubarkan untuk selanjutnya mengikuti pelajaran selanjutnya.

\section{2) Pertemuan II}

Pelaksanaan tindakan tersebut adalah sebagai berikut : 
a) Peneliti dan kolabolator menyiapkan siswa

b) Peneliti dan kolabolator menyampaikan motivasi dan tujuan pembelajaran

c) Peneliti dan kolabolator melanjutkan dengan pemanasan serta peregangan otot

d) Peneliti dan kolabolator memulai pembelajaran dengan mengulang materi yang telah disampaikan pada pertemuan sebelumnya

e) Melakukan permainan 3 lawan 3 dan 4 lawan 4 dengan menggunakan pendekatan TGfU

f) Di akhir pertemuan peneliti dan kolabolator melakukan evaluasi tehadap hasil pembelajaran

g) Peneliti dan kolabolator mengakhiri pelajaran dengan berdoa dan siswa dibubarkan untuk mengikuti pelajaran selanjutnya.

\section{3) Pertemuan III}

a) Peneliti dan kolabolator menyiapkan siswan

b) Peneliti dan kolabolator menyampaikan motivasi dan tujuan pembelajaran

c) Peneliti dan kolabolator melanjutkan dengan pemanasan

d) Peneliti dan kolabolator memulai pembelajaran dengan mengulang materi yang telah disampaikan pada pertemuan sebelumnya

e) Melakukan permainan 3 lawan 3 dan 4 lawan 4 dengan menggunakan pendekatan pembelajaran TGfU

f) Di akhir pertemuan peneliti dan kolabolator melakukan evaluasi terhadap hasil pembelajaran

g) Peneliti dan kolabolator mengakhiri pembelajaran dengan berdoa dan siswa dibubarkan untuk mengikuti pembelajaran selanjutnya 
Meningkatkan Hasil Belajar Bermain Tonnis Melalui Pendekatan Teaching Game for Understanding (TGfU)

\section{c. Observasi dan Interprestasi Tindakan I}

Tabel 1 Prosentase Ketuntasan pada Siklus I

\begin{tabular}{cllcc}
\hline $\begin{array}{c}\text { Rentang } \\
\text { Nilai }\end{array}$ & Keterangan & Kriteria & $\begin{array}{c}\text { Jumlah } \\
\text { Anak }\end{array}$ & Prosentase \\
\hline $90-100$ & Baik Sekali & Tuntas & 0 & $0 \%$ \\
\hline $80-89,9$ & Baik & Tuntas & 3 & $13,63 \%$ \\
\hline $70-79,9$ & Cukup & Tuntas \& Tidak Tuntas & 16 & $72,72 \%$ \\
\hline $60-69,9$ & Kurang & Tuntas Tuntas & 3 & $13,63 \%$ \\
\hline$<60$ & $\begin{array}{l}\text { Kurang } \\
\text { Sekali }\end{array}$ & Tidak Tuntas & 0 & $0 \%$ \\
\hline \multicolumn{2}{c}{ Jumlah } & $\mathbf{2 2}$ & $\mathbf{1 0 0} \%$ \\
\hline
\end{tabular}

(Sumber: Data penelitian)

Jika diinterpretasikan dalam bentuk diagram adalah sebagai berikut:

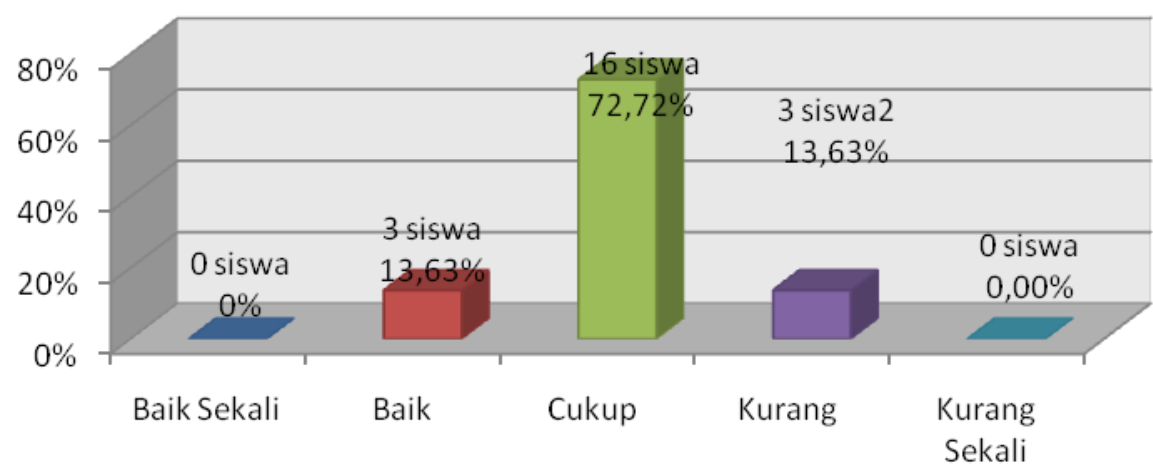

Gambar 1 Prosentase Ketuntasan pada Siklus I

Berdasarkan hasil pengamatan/ observasi selama pelaksanaan Tindakan I berlangsung berdasarkan hasil pekerjaan siswa dapat diidentifikasi:

a) Hasil belajar siswa dalam materi bermain tonnis setelah tindakan I dilakukan menunjukkan hasil bahwa yang mencapai kriteria baik $13,63 \%$, cukup $72,72 \%$, kurang $13,63 \%$.

b) Dalam hal ini sejumlah 13 siswa telah masuk dalam kriteria tuntas, sedangkan 9 siswa Tidak Tuntas. 


\section{d. Analisis dan Refleksi Tindakan I}

Berdasarkan hasil belajar yang dicapai siswa pada siklus I dapat diketahui bahwa masih belum sesuai dengan target capaian pada siklus I, sehingga pembelajaran perlu dilanjutkan pada siklus berikutnya.

\section{e. Deskripsi Data Tindakan I}

Berdasarkan hasil deskripsi data awal, hasil belajar permainan bola kecil tonnis siswa kelas IV SD Negeri 02 Gedong Karanganyar tahun ajaran 2013 / 2014 setelah diberikan tindakan I adalah baik sekali dengan prosentase sebesar $0 \%$, baik $13,63 \%$, cukup sebesar $68,18 \%$, dan kurang sebesar $13,63 \%$, dan kurang sekali sebesar $0 \%$. Sejumlah 13 siswa telah masuk katagori tuntas, sedangkan 9 siswa tidak tuntas.

\section{Siklus II}

Siklus II merupakan, tidak lanjut dari hasil analisis dan refleksi yang dilakukan pada Siklus I, dimana dalam pelaksanaan tindakan dalam Siklus I, rata-rata siswa menunjukkan hasil yang kurang maksimal dan sesuai dengan kriteria yang telah ditentukan pada siklus I.

\section{a. Perencanaan Tindakan II}

Kegiatan perencanaan Tindakan II dilaksanakan setelah pertemuan kedua siklus 1 .

Rencana pelaksanaan tindakan Siklus II sebagai berikut :

a) Peneliti bersama kolabolator merancang skenario pembelajaran bermain tonnis penggunaan pendekatan TGfU,

b) Peneliti dan kolabolator penyusun Rencana Pelaksanaan Pembelajaran (RPP) Siklus II

c) Peneliti dan kolabolator menyiapkan media

d) Peneliti dan kolabolator menyusun instrumen pembelajaran menggunakan GPAl

e) Peneliti dan kolabolator menentukan lokasi pelaksanaan tindakan yaitu di lapangan badminton

b. Pelaksanaan Tindakan II

Tindakan II dilaksanakan selama 2 kali pertemuan. Masingmasing pertemuan dilaksanakan selama $2 \times 35$ menit. 


\section{a) Pertemuan I}

Materi pada pelaksanaan tindakan II :

1) Peneliti dan kolabolator menyiapkan siswa

2) Peneliti dan kolabolator menyampaikan motivasi dan tujuan pembelajaran

3) Peneliti dan kolabolator menyampaikan materi pembelajaran

4) Siswa melakukan permainan tonnis 3 lawan 3 sasaran dan 2 lawan 2

5) Peneliti dan kolabolator memberikan evaluasi terhadap pelaksanaan pembelajaran

6) Di akhir pertemuan peneliti dan kolabolator melakukan evaluasi tehadap hasil pembelajaran yang telah dilakukan serta memberikan informasi mengenai materi yang akan disampaikan minggu depan.

\section{b) Pertemuan II}

Materi pada pelaksanaan tindakan II, pertemuan kedua:

1) Peneliti dan kolabolator menyiapkan siswa dan berdoa

2) Peneliti dan kolabolator menyampaikan motivasi dan tujuan pembelajaran

3) Peneliti dan kolabolator memulai proses pembelajaran diawali dengan proses stretching atau penguluran

4) Siswa diberikan materi pengulangan permainan 3 lawan 3 sasaran dan 2 lawan 2 dengan menggunakan pendekatan TGfU

5) Di akhir pertemuan peneliti dan guru melakukan evaluasi tehadap hasil pembelajaran yang telah dilakukan 


\section{c. Observasi dan Interprestasi Tindakan II}

Tabel 2 Prosentase Ketuntasan pada Siklus II

\begin{tabular}{cllcc}
\hline $\begin{array}{c}\text { Rentang } \\
\text { Nilai }\end{array}$ & Keterangan & \multicolumn{1}{c}{ Kriteria } & $\begin{array}{c}\text { Jumlah } \\
\text { Anak }\end{array}$ & Prosentase \\
\hline $90-100$ & Baik Sekali & Tuntas & 0 & $0 \%$ \\
\hline $80-89,9$ & Baik & Tuntas & 14 & $63,63 \%$ \\
\hline $70-79,9$ & Cukup & Tuntas \& Tidak Tuntas & 8 & $36,36 \%$ \\
\hline $60-69,9$ & Kurang & Tuntas Tuntas & 0 & $0 \%$ \\
\hline$<60$ & Kurang & Tidak Tuntas & 0 & $0 \%$ \\
\hline \multicolumn{2}{c}{ Sekali } & Jumlah & $\mathbf{2 2}$ & $\mathbf{1 0 0 \%}$ \\
\hline
\end{tabular}

(Sumber: Data penelitian)

Jika diinterpretasikan dalam bentuk diagram adalah sebagai berikut:

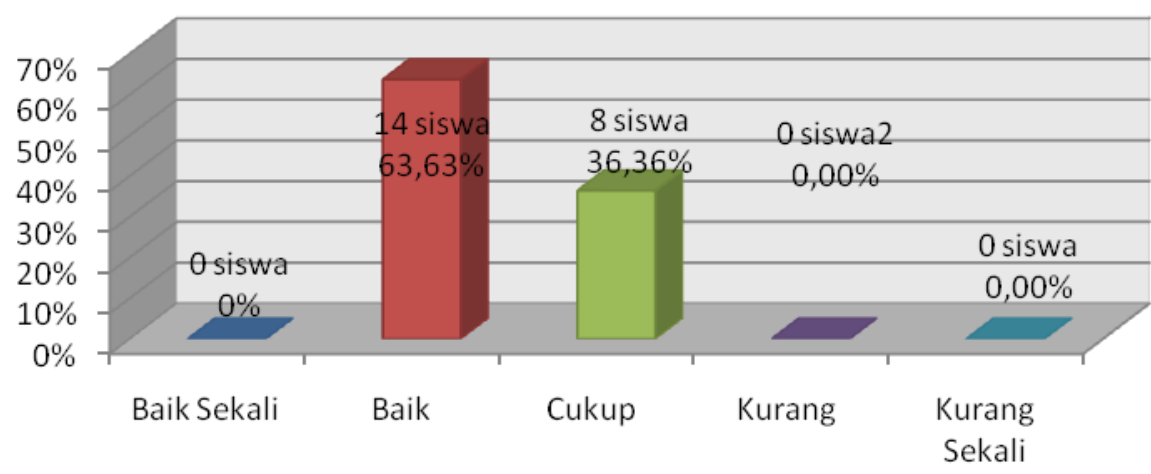

Gambar 1 Prosentase Ketuntasan pada Siklus II

Berdasarkan hasil pengamatan / observasi selama pelaksanaan Tindakan II berlangsung dapat diidentifikasi:

1) Hasil belajar siswa dalam materi permainan bola kecil tonnis setelah tindakan II dilakukan menunjukkan hasil bahwa yang mencapai kriteria baik $63,63 \%$, Cukup $36,36 \%$.

2) Dalam hal ini sejumlah 18 siswa telah masuk dalam kriteria tuntas, sedangkan 4 siswa tidak tuntas.

\section{d. Analisis dan Refleksi Tindakan II}

a) Jumlah dan frekuensi pertemuan pada Siklus II telah menujukan hasil yang sesuai

b) Pelaksanaan proses belajar mengajar telah sesuai dengan rencana yang dibuat pada Rencana Pelaksanaan Pembelajaran (RPP) Siklus II 
c) Motivasi dan antusias siswa selama mengikuti proses belajar mengajar pada tindakan II, cenderung naik.

3) Hasil pekerjaan siswa pada pelaksanaan tindakan ii menunjukkan hasil yang meningkat dibandingkan dengan hasil yang diperoleh pada siklus i. secara lebih detail hasil kerja siswa selama tindakan ii, dijelaskan sebagai berikut: hasil belajar siswa dalam materi bermain tonnis setelah tindakan ii dilakukan menunjukan hasil bahwa yang mencapai kriteria baik 63,63\%, cukup 36,36\%, sedangkan sisanya cukup dan kurang $0 \%$. sejumlah 18 siswa mencapai kriteria tuntas sedangkan 4 siswa tidak tuntas.

\section{e. Deskripsi Data Tindakan II}

Berdasarkan hasil deskripsi data awal, hasil bermainan bola kecil Tonnis siswa kelas IV SD Negeri 02 Gedong Karanganyar tahun ajaran 2013 / 2014 setelah diberikan tindakan II adalah baik sekali dengan prosentase sebesar $0 \%$, baik sebesar $63,63 \%$, cukup sebesar $36,36 \%$, kurang sebesar $0 \%$, dan kurang sekali sebesar $0 \%$. Sejumlah 18 siswa telah masuk kriteria tuntas, sedangkan 4 siswa tidak tuntas.

\section{Pembahasan}

Hasil analisis yang diperoleh peningkatan yang signifikan terjadi pada prasiklus ke siklus I dan dari siklus I ke siklus II. Pada prasiklus hasil belajar bermain tonnis pada kategori cukup sebesar 40,90\%, kurang $36,36 \%$, dan kurang sekali $22,72 \%$ jumlah siswa yang tuntas adalah 6 siswa dan 16 siswa Tidak Tuntas. Pada siklus I hasil belajar bermain tonnis pada kategori baik sebesar 13,63 \%, cukup 68,18\% dan kurang $13,63 \%$, jumlah siswa yang tuntas adalah 13 siswa dan tidak tuntas 9 siswa. Sedangkan pada siklus II hasil belajar bermain tonnis pada kategori baik $63,63 \%$, dan cukup $36,36 \%$, jumlah siswa yang tuntas adalah 18 siswa dan tidak tuntas 4 siswa. 


\section{KESIMPULAN DAN SARAN}

\section{Kesimpulan}

Pembelajaran bermain tonnis menggunakan pendektan pembelajaran Teaching Game for Understanding (TGfU) dapat meningkatkan hasil belajar bermain tonnis siswa kelas VI SD Negeri 02 Gedong Karanganyar tahun pelajaran 2013 / 2014.

\section{Saran}

Berdasarkan hasil penelitian, maka dapat disarankan beberapa hal, khususnya pada guru SD Negeri 02 Gedong Karanganyar, sebagai berikut:

1. Guru hendaknya terus berusaha untuk meningkatkan kemampuannya dalam mengembangkan materi, menyampaikan materi, serta dalam mengelola kelas, sehingga kualitas pembelajaran yang dilakukannya dapat terus meningkat seiring dengan peningkatan kemampuan yang dimilikinya.

2. Guru hendaknya mau membuka diri untuk menerima berbagai bentuk masukan, saran, dan kritikan agar dapat lebih memperbaiki kualitas mengajarnya.

3. Guru hendaknya lebih inovatif dalam menerapkan metode untuk menyampaikan materi pembelajaran.

4. Sekolah hendaknya berusaha menyediakan fasilitas yang dapat mendukung kelancaran kegiatan belajar mengajar.

5. Kepada guru yang belum menerapkan model pembelajaran dengan pendekatan TGfU hendaknya mencoba pendekatan tersebut dalam pembelajaran Penjas sehingga nantinya dapat bermanfaat untuk meningkatkan hasil belajar anak didiknya.

6. Penelitian ini dapat diterapkan di kelas lain maupun di sekolah lain. Namun tentu saja dalam penerapannya harus diikuti oleh penyesuaian dan modifikasi seperlunya sesuai dengan konteks kelas ataupun sekolah masing-masing. Hal ini disebabkan meskipun sekolah-sekolah yang ada di Indonesia ini pada dasarnya hampir sama satu dengan yang lainnya, namun tetap memiliki 
suatu karakteristik khusus yang hanya dimiliki oleh masing-masing kelas atau sekolah sebagai akibat dari keanekaragaman yang dimiliki oleh masing-masing individu yang ada di kelas atau sekolah tersebut.

\section{DAFTAR PUSTAKA}

Aqib, Z. 2009. Penelitian Tindakan Kelas untuk Guru. Bandung: Penerbit Yama Widya.

Griffin, L.L. dan Butler J.I. 2005. Teaching Game For Understanding (TGFU) (Theory, Research, and Practice).

Kristiyanto, A. 2010. Penelitian Tindakan Kelas (PTK) Dalam Pendidikan Jasmani \& Kepelatihan Olahraga. Surakarta: UNS Press

Memmert and Harvey, 2008. Journal of Teaching In Physical Education. Human kinetics, Inc.

Nuharsono, T dan Haryono, S. 2006. Permainan Tonnis. FIK: UNNES.

Sukintaka. 2001. Pembelajaran Teaching Game for Understanding (TGfU): UNY.

Thoriq. 2011. Teaching Game for Understanding (TGfU). Diperoleh 20 januari 2014, dari thoriqsiap55.blogsport.com/2011/10/tgfu.html 